\title{
A Potential Role of the Curry Spice Curcumin in Alzheimer's Disease
}

\author{
John M. Ringman ${ }^{1, *}$, Sally A. Frautschy ${ }^{2}$, Gregory M. Cole ${ }^{2}$, Donna L. Masterman ${ }^{3}$ and \\ Jeffrey L. Cummings ${ }^{1,4}$
}

FINAI.

${ }^{1}$ University of California, Los Angeles, Dept. of Neurology, Alzheimer's Disease Research Center, Los Angeles, CA, ${ }^{2}$ University of California, Los Angeles, Dept. of Medicine and the Greater Los Angeles VA Healthcare System, Geriatric Research, Education, and Clinical Center, Sepulveda, CA, ${ }^{3}$ Amgen, Inc., Thousand Oaks, CA, ${ }^{4}$ University of California, Los Angeles, Dept. of Psychiatry and Biobehavioral Sciences, Los Angeles, CA, USA

\begin{abstract}
There is substantial in-vitro data indicating that curcumin has antioxidant, anti-inflammatory, and anti-amyloid activity. In addition, studies in animal models of Alzheimer's disease (AD) indicate a direct effect of curcumin in decreasing the amyloid pathology of $\mathrm{AD}$. As the widespread use of curcumin as a food additive and relatively small shortterm studies in humans suggest safety, curcumin is a promising agent in the treatment and/or prevention of AD. Nonetheless, important information regarding curcumin bioavailability, safety and tolerability, particularly in an elderly population is lacking. We are therefore performing a study of curcumin in patients with AD to gather this information in addition to data on the effect of curcumin on biomarkers of AD pathology.
\end{abstract}

\section{INTRODUCTION}

Preparations of the plant Curcuma longa Linn have been used to treat various ailments for centuries in Ayurvedic medicine, a traditional Indian system of healing(1). This plant, also known as turmeric, is a member of the Zingiberaceae, or ginger family. Within Ayurveda, turmeric preparations are taken orally to treat dyspepsia, flatulence, liver disease, urinary tract disease and as a "blood purifier." It is also used externally for pemphigus and other skin diseases, and may be inhaled for the treatment of coryza. Components of turmeric are currently undergoing scientific evaluation for their utility as anti-inflammatory agents(2), value in preventing and treating cancer $(3,4)$, for the treatment of human immunodeficiency virus (HIV) infection(2) and most recently for the treatment of cystic fibrosis(5). In addition to its medicinal applications, turmeric is used as a dye and food additive. Originally valued because of its ability to maintain the freshness of food, it is a spice commonly used in curry which is currently its most important commercial application.

Curcuma longa Linn is indigenous to South and Southeast Asia where it is grown for commercial use. Turmeric is derived from the rhizome, or root of the plant. Curcumin was isolated in 1815 and the chemical structure was subsequently identified to be diferuloylmethane (Fig. 1). Along with the other curcuminoids (demethoxycurcumin, bisdemethoxycurcumin, and cyclocurcumin), it composes a yellow pigment that is poorly soluble in water and comprises $3-5 \%$ of turmeric extract(1). Curcumin has a structure similar to Congo Red (Fig. 1) and, like Congo Red, it binds to and stains amyloid plaques in vivo (unpublished observations). It has

*Address correspondence to this author at the UCLA Dept. of Neurology, Alzheimer's Disease Research Center, 710 Westwood Plaza, Suite 2-238, Los Angeles, CA 90095-1769, USA; Tel: (310)-206-2867; Fax: (310)-2065287; Email: jringman@mednet.ucla.edu
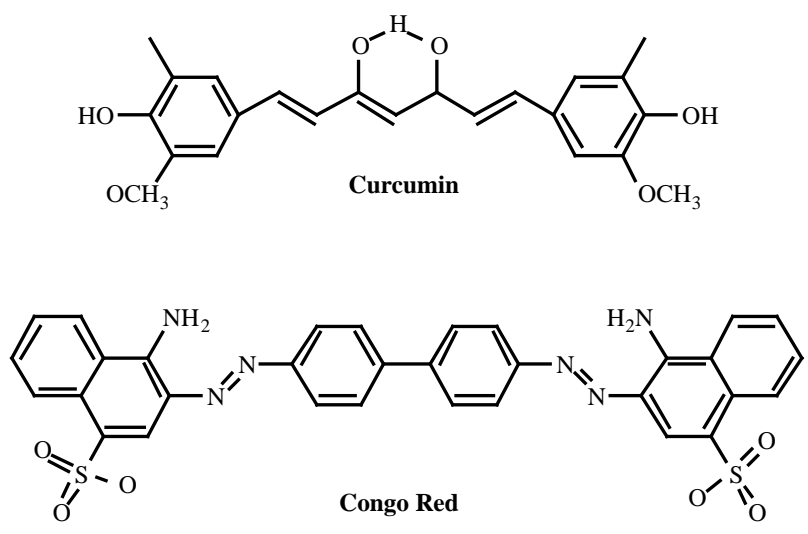

Fig. (1). Chemical structures of Curcumin and Congo Red.

been demonstrated in various experimental preparations to have anti-oxidant, anti-inflammatory, and cholesterollowering properties (see below), all three of which are felt to be key processes involved in the pathogenesis of Alzheimer's disease (AD). Epidemiological studies in India, a country where turmeric consumption is widespread, suggest it has one of the lowest prevalence rates of $\mathrm{AD}$ in the world $(6,7)$. Though there are many potential explanations for this observation, a preventative role of curcumin is a possibility. In this paper we summarize the evidence supporting the evaluation of a role for curcumin in the prevention and treatment of human AD.

\section{IN-VITRO STUDIES}

\section{Antioxidant Properties}

There is a body of convergent evidence suggesting that oxidative damage plays an important role in the pathogenesis of AD. Elevated levels of the oxidated forms of various organic molecules (lipids, proteins, DNA, and carbohydrates)

C2005 Bentham Science Publishers Ltd. 
have been described in brain, cerebrospinal fluid (CSF), blood, and/or urine of $\operatorname{AD}$ patients $(8,9)$. Epidemiological studies have demonstrated an association between dietary antioxidant consumption and a lowered risk for the development of $\mathrm{AD}(10)$ although not all have confirmed this observation(11). At least one clinical trial suggested a possible benefit for the anti-oxidant alpha-tocopherol (vitamin E) in slowing the progression of established $\mathrm{AD}(12)$. Curcumin exerts potent antioxidant activity, the property that led to its early use as a food preservative.

Using a rat liver microsome preparation, Reddy and Lokesh(13) demonstrated that curcumin inhibited lipid peroxidation and Sreejayan and $\operatorname{Rao}(14)$ replicated this in a distinct in-vitro model, demonstrating that curcumin, demethoxycurcumin, and desmethoxycurcumin were more potent antioxidants than alpha-tocopherol. Shih and Lin(15) showed that curcumin prevented oxidative damage of DNA in mouse fibroblasts. Kim et al (16) showed that the curcuminoids were more potent antioxidants than alphatocopherol using a 2,2-diphenyl-1-picrylhydrazyl (DPPH) radical trapping assay in which the ability of the compounds to reduce a radical cation is assessed. Multiple experiments therefore provide evidence that curcumin has substantial antioxidant properties.

\section{Anti-Inflammatory Effects}

Inflammatory changes (e.g. upregulation of complement, cytokines, acute phase reactants) have been identified in AD brain and inflammation is thought to play a compounding, if not causative role in AD pathogenesis(17). Furthermore, epidemiological studies have consistently demonstrated an association between non-steroidal anti-inflammatory drug (NSAID) use and a subsequent decreased risk for the development of $\operatorname{AD}(18,19)$ though studies of NSAIDs in persons with established AD have been disappointing(20). Curcumin has been shown to have anti-inflammatory effects and may have a role in slowing $\mathrm{AD}$ through this mechanism.

Investigators have demonstrated that curcumin inhibits lipoxygenase and cyclooxygenase 2 , enzymes that are responsible for the synthesis of the pro-inflammatory leukotrienes, prostaglandins, and thromboxanes(21). It also inhibits AP-1 mediated transcription related to cytokine regulation in vitro(22) and suppresses inducible nitric oxide synthase (iNOS) in activated macrophages(23), processes that promote inflammation. As lipid peroxides also promote inflammation, curcumin's antioxidant effects also serve to decrease inflammation.

\section{Cholesterol-Lowering Properties}

Cholesterol has an influence on $\beta$-amyloid (A $\beta)$ deposition and prior use of medications that inhibit the enzyme involved in cholesterol synthesis (3-hydroxy-3methylglutaryl-coenzyme $\mathrm{A}$, or $\mathrm{HMG}-\mathrm{CoA}$ reductase inhibitors) have been associated with a decreased risk of AD in epidemiological studies(24). It is proposed that cholesterol interacts with the amyloid cascade in the pathogenesis of AD and studies of drugs affecting cholesterol metabolism for the treatment of $\mathrm{AD}$ are being performed. In one study, administration of $500 \mathrm{mg}$ of curcuminoids a day for 7 days reduced levels of serum cholesterol and lipid peroxides in healthy volunteers(25). This suggests another mechanism by which curcumin might exert beneficial effects on AD.

\section{Hemostatic Properties}

Curcumin has been demonstrated to exert an inhibitory effect on platelet aggregation that has been attributed to its inhibitory effect on thromboxane $A_{2}$ production $(26,27)$. Vascular factors are posited to play a role in $\mathrm{AD}$ or in the manifestations of dementia and inhibitors of platelet aggregation may be of benefit.

\section{Anti-Amyloid Properties}

There is convergent evidence that toxic effects of $A \beta$ on normal cellular function and viability underlay the pathogenesis of $\mathrm{AD}$. $\mathrm{A} \beta_{1-42}$ has been demonstrated to have adverse effects in a number of cell culture models. Kim et al(16) demonstrated that curcuminoids, but not alpha-tocopherol, protected PC12 rat pheochromocytoma and human umbilical vein endothelial cells from $A \beta_{1-42}$ injury. These authors speculated that curcumin's antioxidant properties mediated this effect (see above).

As aggregation of $A \beta$ into fibrils and the subsequent formation of amyloid plaques are posited by many to be important steps in the pathogenesis of $\mathrm{AD}$, these processes are potential targets for therapy. Ono et al(28) performed an invitro study in which they measured the effects of curcumin on formation of $A \beta$ fibrils from $A \beta_{1-40}$ and $A \beta_{1-42}$ peptides. They found that curcumin inhibited the formation and extension of $A \beta$ fibrils and destabilized preformed $A \beta$ fibrils in a dose-dependent fashion at a range between 0.1 and 1 micromolar concentration. We have independently confirmed this finding (in press). Additional experiments suggested that curcumin's effect did not depend on specipic epitopes of $A \beta$ but rather the compound bound to fibrillar $A \beta$ regardless of the specific $A \beta$ sequences of which it was composed.

We have also demonstrated that the in-vitro prevention of $\mathrm{A} \beta$ fibril formation by curcumin is visualizable by electron microscopy. Furthermore, curcumin inhibits the formation of antibody-detectable $\mathrm{A} \beta$ oligomers(29), which are felt to be intermediates in $\mathrm{A} \beta$ aggregation (in press).

Thus curcumin appears to have primary effects on $\mathrm{A} \beta$ aggregation in addition to its antioxidant, anti-inflammatory, and platelet aggregation inhibiting properties.

\section{ANIMAL STUDIES}

\section{Pharmacokinetic and Pharmacodynamic Studies}

In rats, $75 \%$ of an orally administered dose $(1 \mathrm{gram} / \mathrm{kg}$ body weight) was recovered in the feces with only negligible amounts being detected in blood and urine. High doses of curcumin (400 mg or $3.6 \mathrm{mmol} / \mathrm{kg}$ body weight) are required to obtain detectable tissue levels in rats(3). This is attributed to extensive metabolism of the compound in the gastrointestinal wall, glucoronidation in the liver, and enterohepatic circulation. There are few published data on central nervous system penetration of curcumin in animals. 


\section{Safety Studies}

Single doses of $13.6 \mathrm{mmol} / \mathrm{kg}$ body weight did not cause any clinical signs in rats(30). Rats treated with up to 3,500 $\mathrm{mg} / \mathrm{kg}$ body weight per day $(9.5 \mathrm{mmol} / \mathrm{kg}$ body weight) for 90 days displayed only discolored feces, yellow fur, and hematological changes not considered biologically significant(3). A study in dogs similarly showed lack of toxicity(3). An independent study of rats $(1000 \mathrm{mg} / \mathrm{kg} /$ day $)$ and monkeys $(800 \mathrm{mg} / \mathrm{kg} /$ day $)$ for 3 months failed to reveal any evidence of adverse effects on growth, behavioral, biochemical, or histopathological parameters(3). Hepatotoxicity was noted in mice that were fed tumeric and ethanolic tumeric extract $(0.05-0.25 \%)$ for 14 days and rats that were fed a higher dose of tumeric (5\%) for 90 days(31).

In some studies curcumin has had ulcerogenic properties, causing gastric ulcerations in rats at doses of $100 \mathrm{mg} / \mathrm{kg}(32)$. Furthermore, in a study of rats treated with $50,000 \mathrm{ppm}$ dietary turmeric oleoresin there was an increased incidence of ulcers, inflammation, and hyperplasia of the forestomach, cecum, and colon(3). In other investigations, however, curcumin had antiulcerogenic properties, causing decreased gastric secretion in rats(33) and it has been traditionally used to treat dyspepsia. It is likely that differences in the dose and preparation of the agent account for these disparate observations.

In one study, female mice receiving 50,000 ppm turmeric oleoresin had a significantly increased incidence of thyroid gland follicular cell hyperplasia(34). Animals studies of carcinogenicity, genotoxicity, and teratogenicity have been equivocal or negative(3).

Animal studies therefore indicate that curcumin at high doses is safe though vigilance is suggested for potential hepatic, gastric, and thyroid toxicity.

\section{HUMAN STUDIES}

\section{Pharmacokinetic Studies}

Human pharmacokinetic studies have been performed in patients with cancer or pre-cancerous lesions. In 15 patients with colon cancer, oral doses of 440-2200 mg were administered daily and curcumin levels measured in the blood, urine, and feces at up to 29 days using high pressure liquid chromatography (HPLC)(35). Though curcumin and its metabolites (curcumin glucuronide, curcumin sulfate, hexahydrocurcumin and hexahydrocurcuminol) were readily measured in feces, none were identifiable in the blood or urine. In another study in patients with precancerous lesions and normal adults, curcumin levels were measured in the blood 2-24 hours after oral ingestion of $500 \mathrm{mg}-8000 \mathrm{mg}$ per day(36). Peak blood levels of 1.77 micromoles were observed 2 hours after the $8000 \mathrm{mg}$ dose with levels decreasing gradually after that. Blood levels in persons receiving $500-2000 \mathrm{mg}$ doses were barely detectable. Two patients had repeat pharmacokinetic studies done after taking curcumin regularly for 1 months' time and no changes were seen in their blood levels. The low blood levels of curcumin seen in this study and the absence of curcumin seen with lower doses are consistent with extensive metabolism of curcumin in the intestinal wall and/or poor absorption. The possibility that curcumin is rapidly metabolized to unmeasured active metabolites would reconcile these findings with the observed biological activity of comparable doses in animal studies. Alternatively, the lack of an internal standard in the HPLC assays used in these studies might render them relatively insensitive to the detection of curcumin(37).

The bioavailability of curcumin may be limited by intestinal and hepatic glucuronidation. Piperine, an inhibitor of glucuronidation, could be administered concomitantly with curcumin to increase bioavailability. Shoba et al demonstrated the feasibility of this approach in both rats and humans(38). When $20 \mathrm{mg}$ of piperine was administered orally with $2 \mathrm{gm}$ of curcumin to volunteers, serum levels were significantly enhanced at 1 hour's time, increasing total bioavailability by 20 -fold. No toxicity was observed in the 10 subjects who participated in this study.

\section{Safety and Tolerability}

Turmeric is currently listed as "generally recognized as safe" (GRAS) as a coloring and flavoring agent in food by the United States Food and Drug Administration (FDA)(39). However, curcumin itself is not listed and has been given a temporary acceptable daily intake level of $0.1 \mathrm{mg} / \mathrm{kg}$ of body weight(40) pending further study. Its widespread use in food without known adverse effects provides support for its safety. In addition, several relatively short-term studies specifically looking at the safety and tolerability of high doses have been performed.

In short-term studies doses of up to $1,200 \mathrm{mg} /$ day were demonstrated to be well-tolerated in patients with rheumatoid arthritis(41), post-surgical patients(42) and ophthalmology patients(43). In a study of 19 patients with acquired immune deficiency syndrome (AIDS) two patients, one of whom had a history of peptic ulcer disease, developed gastric irritation(44).

In a study of patients with colon cancer treated for 4 months(35), 1 patient on 1,320 mg developed nausea in the first month that resolved despite continued administration of the drug and two patients developed diarrhea (one on $880 \mathrm{mg}$ and one on 2,200 mg/day) and dropped out of the study. In the study of patients with pre-cancerous lesions treated for 3 months, doses of up to $8000 \mathrm{mg} /$ day were tolerated well though higher doses were difficult to tolerate due to their bulky volume(36). In summary, high doses of curcumin appear to be well-tolerated with few adverse effects other than gastric irritation or nausea. To date, however, we are not aware of longer-term safety and tolerability studies in humans nor of studies specifically done in an elderly population as would be encountered in a study of AD.

\section{STUDIES IN ANIMAL MODELS OF AD}

In light of the antioxidant, anti-inflammatory, and antiamyloid effects discussed above, curcumin has become a candidate compound for the prevention or treatment of AD. Several animal models for AD pathology currently exist and investigators have performed studies of curcumin in such animals.

Lim et al(45) studied the effects of curcumin in transgenic mice which carry a human mutation in the amyloid precursor protein (APPsw) that causes AD pathology. 
APPsw mice display age-related neuritic plaques, inflammation, oxidative damage, and age-related memory deficits but not neurofibrillary tangle pathology. In this study, ten month old APPsw mice were fed diets containing either no curcumin, low-dose (Sigma, $160 \mathrm{ppm}$ ), or high-dose curcumin $(5000 \mathrm{ppm})$ for 6 months before being sacrificed. Mice fed low-dose curcumin had decreased total microgial activity, decreased cerebral levels of oxidized proteins, and decreased levels of IL-1 $\beta$, a cytokine that has been implicated in agerelated memory loss(46). Most intriguingly, mice fed lowdose curcumin also had significantly reduced levels of soluble and insoluble $A \beta$ as well as a reduced amyloid plaque burden. An additional observation was that the reduction in microglial activity was localized such that increased activity was observed in the area around amyloid plaques, possibly representing a stimulatory effect of curcumin on phagocytosis of plaques by microglia. APPsw mice fed high-dose curcumin displayed similar decreases in IL-1 $\beta$ and oxidized proteins but no change in $A \beta$. One possible explanation for the unanticipated results between the low- and high-dose groups is that the multiple mechanisms of action that curcumin has have different dose requirements and time courses that may counterbalance each other at higher doses. More recently we have replicated the effect of low dose curcumin on insoluble $A \beta$ levels in more aged APPsw mice in which AD-like pathology is established (unpublished observations).

Similar effects of curcumin were observed in an animal model of $A D$ in which human $A \beta_{1-40}$ and $A \beta_{1-42}$ were infused with a lipoprotein chaperone into the cerebral ventricles of aged female rats(47). Such rats develop A $\beta$ deposits, neurodegeneration, and memory impairment. Reduced levels of $8-\mathrm{EPI}-\mathrm{F}_{2}$ isoprostanes, an oxidative produce of arachidonic acid, and normal levels of synaptophysin, a marker of synaptic integrity were seen in curcumin (2000 ppm), but not ibuprofen-fed rats. Both curcumin and ibuprofen-fed rats had decreased microglial activity. Increased microglial staining was seen in areas surrounding amyloid plaques. We also measured the spatial memory and post-synaptic density 95 (PSD-95) levels, a synaptic protein that anchors N-methyl$D$ - aspartate (NMDA) receptors, in the brains of younger rats infused with a higher dose of $A \beta_{1-40}$ and $A \beta_{1-42}$. Rats fed with curcumin $(500 \mathrm{ppm})$ showed reduced path length and latency in finding the hidden platform in the Morris water maze test, demonstrating superior memory function compared to control-fed rats. Increased PSD-95 and decreased A $\beta$-stained area also were seen in curcumin-fed rats. These studies suggest that curcumin ameliorates both the pathology and cognitive deficits induced by $\mathrm{A} \beta$ infusion in rats.

These findings provide evidence that curcumin can ameliorate the pathology and cognitive deficits in animal models of $\mathrm{AD}$ but leaves the mechanism for this activity open to question. We have performed subsequent fluorescence studies that demonstrate that curcumin binds to amyloid plaques in human $\mathrm{AD}$ and $\mathrm{Tg} 2576$ transgenic mouse brain tissue invitro. Furthermore, curcumin was found to bind to amyloid plaques when such mice were either fed curcumin or curcumin injected in the carotid artery (in press). This demonstrates that curcumin crosses the blood-brain barrier in these mice, and direct binding to plaques may be important in its anti-amyloid activity. Animal studies therefore are highly suggestive of efficacy against $\mathrm{AD}$ pathology via multiple possible mechanisms. Further study of curcumin in the treatment or prevention of $\mathrm{AD}$ in humans is warranted.

\section{A PHASE II, DOUBLE-BLIND, PLACEBO- CONTROLLED STUDY OF THE SAFETY AND TOLERABILITY OF TWO DOSES OF CURCUMIN C3 COMPLEX® VERSUS PLACEBO IN PATIENTS WITH MILD-TO-MODERATE ALZHEIMER'S DISEASE}

\section{Introduction}

We are performing a 24 week, randomized, doubleblinded, placebo-controlled study of two doses of curcumin in persons with mild-to-moderate $\mathrm{AD}$. This will be followed by a 24 week extension study in which subjects on curcumin will continue treatment at their assigned dose and those on placebo will receive one of the two doses of curcumin. The purposes of this study are to:

1) To determine the safety and tolerability of $2000 \mathrm{mg}$ and $4000 \mathrm{mg} /$ day of Curcumin C3 Complex ${ }^{\circledR}$ in patients with AD treated for $6-12$ months.

2) To obtain pharmacokinetic data including central nervous system penetration on subjects with $\mathrm{AD}$ receiving these doses of orally adminstered Curcumin C3 Complex ${ }^{\circledR}$.

3) To gather data on the effects of curcumin on biomarkers thought to be related to the pathology $\mathrm{AD}$ and the mechanism of action of curcumin (cholesterol levels, CSF isoprostanes, alpha-1-antichymotrypsin, C-reactive protein, tau, $A \beta_{1-40}$ and $A \beta_{1-42}$ )

4) To gather preliminary efficacy data (Alzheimer's Disease Assessment Scale, cognitive subscale (ADASCog), Neuropsychiatric Inventory (NPI), Activities of Daily Living Scale (ADCS-ADL)) of curcumin in AD.

\section{Design}

Thirty-three subjects with mild-to-moderate AD (MiniMental Status Examination, or MMSE, scores between 18 and 28, inclusive) defined by National Institute for Neurological and Communicative Disorders and Stroke - Alzheimer's Disease and Related Disorders Association (NINCDS-ARDA) criteria will be randomized (11 per arm). Subjects may be on stable doses of a cholinesterase inhibitor or memantine but may not be on high doses of antioxidants or anti-inflammatory medications. Subjects will undergo a lumbar puncture at the baseline visit for assessment of biomarker levels and receive either placebo, $2000 \mathrm{mg}$ or 4000 mg Curcumin C3 Complex to be taken in two divided doses each day. These doses were chosen to in an effort to achieve measurable CSF levels of curcumin while maximizing tolerability. Blood draws for toxicological monitoring (CBC, Chemistry Panel, LFTs. PT, PTT, TFTs) will be obtained at screening, 4 week, 12 week, 24 week, 36 week, and 48 week visits. Adverse effects will be assessed with a questionnaire which will be administered at baseline, 4 week, 12 week, 24 week, 36 week, and 48 week visits. Subjects also will be administered the MMSE, ADASCog, NPI, and ADCS-ADL scale at baseline, 24 weeks' and 48 weeks' time. At the 24week visit, subjects will be admitted to the Clinical Research Center and have baseline blood drawn prior to taking their 
a.m. dose of study medication. They will then undergo serial blood draws for curcumin levels in addition to a second lumbar puncture to again assess biomarker levels and CSF levels of curcumin. Subjects on placebo will then be placed on either of the two doses of curcumin and all subjects will be followed for an additional 24 weeks. The primary analysis will be an intent-to-treat analysis using last-observationcarried-forward data in case of drop-outs. Two tailed T-tests with a significance cut-off of 0.05 will be used

\section{CONCLUSIONS}

There is substantial in-vitro data indicating that curcumin has antioxidant, anti-inflammatory, and anti-amyloid activity. In addition, studies in animal models of AD indicate a direct effect of curcumin in decreasing the amyloid pathology of AD. As the widespread use of curcumin as a food additive and relatively small short-term studies in humans suggest safety, curcumin is a promising agent in the treatment and/or prevention of AD. Nonetheless, important information regarding curcumin bioavailability, safety and tolerability, particularly in an elderly population is lacking. We are therefore performing a study of curcumin in patients with $\mathrm{AD}$ to gather this information in addition to data on the effect of curcumin on biomarkers of AD pathology.

\section{ACKNOWLEDGEMENTS}

NIA ADRC Grant AG 16570, Institute for the Study on Aging, John Douglas French Foundation, and the Shirley and Jack Goldberg Trust

\section{REFERENCES}

[1] Majeed M, Badmaev V, Murrray F. Turmeric and the Healing Curcuminoids. New Canaan, CT: Keats Publishing, Inc.; 1996.

[2] Vlietinck AJ, De Bruyne T, Apers S, Pieters LA. Plant-derived leading compounds for chemotherapy of human immunodeficiency virus (HIV) infection. Planta Med 1998;64(2):97-109.

[3] Kelloff GJ, Crowell JA, Hawk ET, Steele VE, Lubet RA, Boone $\mathrm{CW}$, et al. Strategy and planning for chemopreventive drug development: clinical development plans II. J Cell Biochem Suppl 1996;26:54-71.

[4] Aggarwal BB, Kumar A, Bharti AC. Anticancer potential of curcumin: preclinical and clinical studies. Anticancer Res 2003;23(1A):363-98.

[5] Egan ME, Pearson M, Weiner SA, Rajendran V, Rubin D, Glockner-Pagel J, et al. Curcumin, a major constituent of turmeric, corrects cystic fibrosis defects. Science 2004;304(5670):600-2.

[6] Chandra V, Pandav R, Dodge HH, Johnston JM, Belle SH, DeKosky ST, et al. Incidence of Alzheimer's disease in a rural community in India: the Indo-US study. Neurology 2001;57(6):985-9.

[7] Vas CJ, Pinto C, Panikker D, Noronha S, Deshpande N, Kulkarni $\mathrm{L}$, et al. Prevalence of dementia in an urban Indian population. Int Psychogeriatr 2001;13(4):439-50.

[8] Tohgi H, Abe T, Yamazaki K, Murata T, Ishizaki E, Isobe C. Alterations of 3-nitrotyrosine concentration in the cerebrospinal fluid during aging and in patients with Alzheimer's disease. Neurosci Lett 1999;269(1):52-4.

[9] Pratico D, Clark CM, Lee VM, Trojanowski JQ, Rokach J, FitzGerald GA. Increased 8,12-iso-iPF2alpha-VI in Alzheimer's disease: correlation of a noninvasive index of lipid peroxidation with disease severity. Ann Neurol 2000;48(5):809-12.

[10] Engelhart MJ, Geerlings MI, Ruitenberg A, van Swieten JC, Hofman A, Witteman JC, et al. Dietary intake of antioxidants and risk of Alzheimer disease. JAMA 2002;287(24):3223-9.

[11] Luchsinger JA, Tang MX, Shea S, Mayeux R. Antioxidant vitamin intake and risk of Alzheimer disease. Arch Neurol 2003;60(2):2038 .
[12] Sano M, Ernesto C, Thomas RG, Klauber MR, Schafer K, Grundman M, et al. A controlled trial of selegiline, alpha-tocopherol, or both as treatment for Alzheimer's disease. The Alzheimer's Disease Cooperative Study. N Engl J Med 1997;336(17):1216-22.

[13] Reddy AC, Lokesh BR. Studies on spice principles as antioxidants in the inhibition of lipid peroxidation of rat liver microsomes. Mol Cell Biochem 1992;111(1-2):117-24.

[14] Sreejayan, Rao MN. Curcuminoids as potent inhibitors of lipid peroxidation. J Pharm Pharmacol 1994;46(12):1013-6.

[15] Shih CA, Lin JK. Inhibition of 8-hydroxydeoxyguanosine formation by curcumin in mouse fibroblast cells. Carcinogenesis 1993;14(4):709-12.

[16] Kim DS, Park SY, Kim JK. Curcuminoids from Curcuma longa L. (Zingiberaceae) that protect $\mathrm{PC} 12$ rat pheochromocytoma and normal human umbilical vein endothelial cells from betaA(1-42) insult. Neurosci Lett 2001;303(1):57-61.

[17] Akiyama H, Barger S, Barnum S, Bradt B, Bauer J, Cole GM, et al. Inflammation and Alzheimer's disease. Neurobiol Aging 2000;21(3):383-421

[18] The Canadian Study of Health and Aging: risk factors for Alzheimer's disease in Canada. Neurology 1994;44(11):2073-80.

[19] Andersen K, Launer LJ, Ott A, Hoes AW, Breteler MM, Hofman A. Do nonsteroidal anti-inflammatory drugs decrease the risk for Alzheimer's disease? The Rotterdam Study. Neurology 1995;45(8):1441-5.

[20] Aisen PS, Schafer KA, Grundman M, Pfeiffer E, Sano M, Davis $\mathrm{KL}$, et al. Effects of rofecoxib or naproxen vs placebo on Alzheimer disease progression: a randomized controlled trial. JAMA 2003;289(21):2819-26.

[21] Ammon HP, Safayhi H, Mack T, Sabieraj J. Mechanism of antiinflammatory actions of curcumine and boswellic acids. J Ethnopharmacol 1993;38(2-3):113-9.

[22] Xu YX, Pindolia KR, Janakiraman N, Chapman RA, Gautam SC. Curcumin inhibits IL1 alpha and TNF-alpha induction of AP-1 and NF-kB DNA-binding activity in bone marrow stromal cells. Hematopathol Mol Hematol 1997;11(1):49-62.

[23] Pan MH, Lin-Shiau SY, Lin JK. Comparative studies on the suppression of nitric oxide synthase by curcumin and its hydrogenated metabolites through down-regulation of IkappaB kinase and NFkappaB activation in macrophages. Biochem Pharmacol 2000;60(11):1665-76.

[24] Puglielli L, Tanzi RE, Kovacs DM. Alzheimer's disease: the cholesterol connection. Nat Neurosci 2003;6(4):345-51.

[25] Soni KB, Kuttan R. Effect of oral curcumin administration on serum peroxides and cholesterol levels in human volunteers. Indian J Physiol Pharmacol 1992;36(4):273-5.

[26] Shah BH, Nawaz Z, Pertani SA, Roomi A, Mahmood H, Saeed SA, et al. Inhibitory effect of curcumin, a food spice from turmeric, on platelet-activating factor- and arachidonic acid-mediated platelet aggregation through inhibition of thromboxane formation and $\mathrm{Ca} 2+$ signaling. Biochem Pharmacol 1999;58(7):1167-72.

[27] Srivastava R, Dikshit M, Srimal RC, Dhawan BN. Anti-thrombotic effect of curcumin. Thromb Res 1985;40(3):413-7.

[28] Ono K, Hasegawa K, Naiki H, Yamada M. Curcumin has potent anti-amyloidogenic effects for Alzheimer's beta-amyloid fibrils in vitro. J Neurosci Res 2004;75(6):742-50.

[29] Kayed R, Head E, Thompson JL, McIntire TM, Milton SC, Cotman $\mathrm{CW}$, et al. Common structure of soluble amyloid oligomers implies common mechanism of pathogenesis. Science 2003;300(5618):486-9.

[30] Wahlstrom B, Blennow G. A study on the fate of curcumin in the rat. Acta Pharmacol Toxicol (Copenh) 1978;43(2):86-92.

[31] Deshpande SS, Lalitha VS, Ingle AD, Raste AS, Gadre SG, Maru GB. Subchronic oral toxicity of turmeric and ethanolic turmeric extract in female mice and rats. Toxicol Lett 1998;95(3):183-93.

[32] Gupta B, Kulshrestha VK, Srivastava RK, Prasad DN. Mechanisms of curcumin induced gastric ulcer in rats. Indian $\mathrm{J}$ Med Res 1980;71:806-14.

[33] Shakai K. Effects of extracts of Zingiberaceae herbs on gastric section in rabbits. Chem Pharm Bull 1982;20(37):215.

[34] NTP Toxicology and Carcinogenesis Studies of Turmeric Oleoresin (CAS No. 8024-37-1) (Major Component 79\%-85\% Curcumin, CAS No. 458-37-7) in F344/N Rats and B6C3F1 Mice (Feed Studies). Natl Toxicol Program Tech Rep Ser 1993;427:1-275.

[35] Sharma RA, McLelland HR, Hill KA, Ireson CR, Euden SA, Manson MM, et al. Pharmacodynamic and pharmacokinetic study of 
oral Curcuma extract in patients with colorectal cancer. Clin Cancer Res 2001;7(7):1894-900.

[36] Cheng AL, Hsu CH, Lin JK, Hsu MM, Ho YF, Shen TS, et al. Phase I clinical trial of curcumin, a chemopreventive agent, in patients with high-risk or pre-malignant lesions. Anticancer Res 2001;21(4B):2895-900.

[37] Heath DD, Pruitt MA, Brenner DE, Rock CL. Curcumin in plasma and urine: quantitation by high-performance liquid chromatography. J Chromatogr B Analyt Technol Biomed Life Sci 2003;783(1):287-95.

[38] Shoba G, Joy D, Joseph T, Majeed M, Rajendran R, Srinivas PS. Influence of piperine on the pharmacokinetics of curcumin in animals and human volunteers. Planta Med 1998;64(4):353-6.

[39] Administration USFaD. Substances generally recognized as safe. Essential oils, oleoresins (solvent-free) and natural extractives (including distillates). 1994.

[40] Shah RG, Netrawali MS. Evaluation of mutagenic activity of turmeric extract containing curcumin, before and after activation with mammalian cecal microbial extract of liver microsomal fraction, in the Ames Salmonella test. Bull Environ Contam Toxicol 1988;40(3):350-7.

[41] Deodhar SD, Sethi R, Srimal RC. Preliminary study on antirheumatic activity of curcumin (diferuloyl methane). Indian J Med Res 1980;71:632-4.
[42] Satoskar RR, Shah SJ, Shenoy SG. Evaluation of antiinflammatory property of curcumin (diferuloyl methane) in patients with postoperative inflammation. Int $\mathrm{J}$ Clin Pharmacol Ther Toxicol 1986;24(12):651-4.

[43] Lal B, Kapoor AK, Agrawal PK, Asthana OP, Srimal RC. Role of curcumin in idiopathic inflammatory orbital pseudotumours. Phytother Res 2000;14(6):443-7.

[44] Chainani-Wu N. Safety and anti-inflammatory activity of curcumin: a component of tumeric (Curcuma longa). J Altern Complement Med 2003;9(1):161-8.

[45] Lim GP, Chu T, Yang F, Beech W, Frautschy SA, Cole GM. The curry spice curcumin reduces oxidative damage and amyloid pathology in an Alzheimer transgenic mouse. $J$ Neurosci 2001;21(21):8370-7.

[46] Murray CA, Lynch MA. Evidence that increased hippocampal expression of the cytokine interleukin-1 beta is a common trigger for age- and stress-induced impairments in long-term potentiation. J Neurosci 1998;18(8):2974-81.

[47] Frautschy SA, Hu W, Kim P, Miller SA, Chu T, Harris-White ME, et al. Phenolic anti-inflammatory antioxidant reversal of Abetainduced cognitive deficits and neuropathology. Neurobiol Aging 2001;22(6):993-1005. 